\title{
Epigenetic roles of PIWI-interacting RNAs (piRNAs) in cancer metastasis (Review)
}

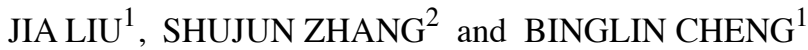 \\ ${ }^{1}$ Department of Integrated Traditional Chinese and Western Medicine Oncology, \\ The First Affiliated Hospital of Harbin Medical University; ${ }^{2}$ Department of Pathology, \\ The Fourth Affiliated Hospital of Harbin Medical University, Harbin, Heilongjiang 150000, P.R. China
}

Received March 19, 2018; Accepted September 3, 2018

DOI: $10.3892 / o r .2018 .6684$

\begin{abstract}
P-element-induced wimpy testis (PIWI)-interacting RNAs (piRNAs) are epigenetic-related short ncRNAs that participate in chromatin regulation, transposon silencing, and modification of specific gene sites. These epigenetic factors or alterations are also involved in the growth of a variety of human cancers, including lung, breast, and colon cancer. Accumulating evidence has revealed that tumor metastasis and invasion involve genetic and epigenetic factors. Cancer metastasis is characterized by epigenetic alterations including DNA methylation and histone modification. Changes in DNA methylation, H3K9me3 heterochromatin and transposable elements have been detected in several cancers. piRNAs may function in gene silencing and gene modification upstream or downstream of oncogenes in cancer cell lines or cancer tissues. In addition to piRNAs, PIWI proteins can be used as biomarkers for prognosis, diagnosis and clinical evaluation and may be factors in cancer metastasis. Here, we elucidated the possible mechanisms by which piRNAs regulate cancer metastasis, including but not restricted to influencing DNA and histone methylation and transposable elements.
\end{abstract}

\section{Contents}

1. Introduction

2. Epigenetic functions of PIWI and piRNAs

3. Epigenetic functions of specific transposable elements

4. Epigenetic functions of specific piRNA pathway proteins

5. piRNAs and PIWI with cancer

6. Epigenetic mechanisms of cancer metastasis related to piRNAs

Correspondence to: Dr Binglin Cheng, Department of Integrated Traditional Chinese and Western Medicine Oncology, The First Affiliated Hospital of Harbin Medical University, 23 Youzheng Street, Nangang, Harbin, Heilongjiang 150000, P.R. China E-mail: chengbinglin1971@126.com

Key words: piRNA, epigenetics, cancer, metastasis
7. Epigenetics of ncRNAs in cancer

8. Discussion

\section{Introduction}

P-element-induced wimpy testis (PIWI)-interacting RNAs (piRNAs) belong to a new class of ncRNAs that have been associated with many cancers (1). piRNAs are involved in the gene regulation process in which certain nucleotides bind coding regions in gene promoters (2). piRNAs function in the epigenetic regulation of DNA methylation (3), transposable silencing and chromatin modification (4). PIWI is a type of Argonaute protein that binds to piRNAs and carries out unique functions in somatic and germ cells, and stably expressed piRNAs have also been detected in human blood (5). piRNAs may be used as biomarkers for cancer diagnosis (6). Four PIWI proteins have been discovered in humans: PIWI1, PIWI2, PIWI3, and PIWI4 (7-10). Furthermore, PIWI expression levels are associated with different types of cancers and clinical stages (11-13). Additionally, piRNAs have been linked to proliferation, apoptosis (14), genomic instability (15), invasion, and metastasis (16) in cancer cells. The levels of PIWI and piRNAs were revealed to be significantly altered between tumor tissues and non-tumor tissues. The clinical pathological features of tumors are associated with PIWI and piRNA expression. Therefore, additional studies are needed to understand the role of piRNAs in cancer and their epigenetic mechanisms and to shed light on the potential of piRNAs for the diagnosis and prediction of clinical cancer stages.

Cancer formation involves genetic, epigenetic, and pathological mechanisms (17). Cancer is a complicated disease with distinct genetic, epigenetic and pathological features (18). Despite recent advancements in precision medicine, the assessment of pathological and clinical features remains the primary and most accurate method for diagnosing carcinoma. Preventing tumor metastasis is still a formidable problem in the world. Carcinogenesis involves genetic machineries that are present beginning in early childhood but are altered over time. Abnormal and inappropriate epigenetic alterations can regulate carcinoma development (19). Activation of oncogenes and inactivation of tumor suppressors or other cell factors and pathways cannot fully account for metastatic cancers. Under 
certain circumstances, epigenetic mechanisms related to piRNAs may be responsible for the downstream inactivation of genes in tumors (20). Epigenetic modifications alter gene expression rather than changing the DNA sequence (21). These alterations are based on DNA methylation and histone protein modification, and non-coding RNAs (ncRNAs) frequently participate in this process.

\section{Epigenetic functions of PIWI and piRNAs}

piRNAs play crucial roles in protecting genomic stability by inhibiting transposon activity and maintaining minimum levels of transposons in germ line, mammalian cells and other cell types (22). piRNAs reside in clusters within heterochromatin-euchromatin boundaries and exhibit repeat-rich regions with ancient fragmented transposon copies. Amplification of piRNAs occurs through the 'ping-pang' cycle (23). This cycle is initiated by the emergence of a primary piRNA from piRNA clusters. Primary piRNAs are antisense sequences to expressed transposons and have the ability to cleave their targets, while secondary piRNAs form the AGO3 complex. The AGO3-bound piRNAs interact with transposon targets, which include antisense transposon sequences. This interaction then produces antisense piRNAs, and the 'ping-pang' cycle continues.

PIWI proteins have been reported to be selectively expressed in precancerous stem cells, tumor cell lines and cells of various malignancies (24). PIWI and Aubergine (Aub) proteins accumulate in the pole plasm and transfer maternal piRNAs into germ line cells (25). It was previously believed that PIWI proteins could maintain genomic integrity in animal germ cells by silencing transposons. Without these proteins, piRNAs cannot inactivate transposons within a single generation. In mammals, the PIWI proteins MILI, MIWI2 and intracisternal A-particle (IAP) act as retrotransposons and function as transposon-inhibiting factors via transposon gene silencing (TGS) (26). MILI is active in the cytosol, and MIWI2 is active in the nucleus (27). MILI, also known as PIWIL2, and MIWI2, also known as PIWIL4, suppress transposons in the cytoplasm and nucleus. MIWI is a slicer similar to Argonaute family members, which include PIWI proteins. The function of the slicer MIWI depends on its binding motif, which has a conserved Argonaute domain sequence (27). A high degree of MIWI complementarity is required for piRNA targeting. MIWI-associated piRNAs endonucleolytically cleave their target RNAs. Therefore, silencing of transposons depends on the piRNAs involved. Using next-generation sequencing, we can analyze histone modifications and methylation across entire genomes. Moreover, we can identify ncRNAs that participate in these regulatory processes. This technology provides a link between epigenetic modifications and transcription (28).

\section{Epigenetic functions of specific transposable elements}

Transcriptional silencing, heterochromatin formation, transgene silencing, HP1 $\alpha$ alterations, histone modifications and transposon suppression are all associated with PIWI, piRNAs, the piRNA pathway and specific transposable elements (29).

As mediators of eukaryotic evolution, transposable elements are classified as either retrotransposons or DNA transposons.
Notably, retrotransposons can cause genomic variations (30), alter chromatin structures and change the expression of nearby genes by integrating into genomic locations. Retrotransposons include long terminal repeat (LTR) and non-LTR retrotransposons. LTRs are similar to retroviruses in their structure, and non-LTRs are similar to mRNAs (31).

LTRs can encode structural proteins to form virus-like particles (VLPs), which can regulate gene transcription. RNA derived from LTRs can be reverse-transcribed into cDNA and can thereby integrate into the genome (32). RNA polymerase II located at the 5'end of LTRs can transcribe LTRs. These RNA molecules are then packaged into viral particles and use the reverse transcription machinery to generate full-length DNA. The first priming event occurs between the 5'end and the 3 'end of LTR, and the second priming event occurs near the 3 'end of LTR leading to production of a double-stranded cDNA molecule through an additional strand transfer. Thus, the cDNA is integrated into the host genome. The main difference between retrotransposons and infectious retroviruses is the presence of the envelope (env) gene in the latter, which enables viruses to infect other cells. In contrast, exon open reading frames (ORFs) are found in retrotransposons and retroviral genomes (33).

Non-LTRs are classified as either autonomous non-LTRs, such as LINEs, or non-autonomous LTRs, such as short interspersed nuclear elements (SINEs) (34). Retrotranspositioncompetent LINE1 includes a 5'-untranslated region (UTR) that is rich in CpG-islands; ORF1, which binds to RNA and ORF2, which encodes proteins such as endonuclease, reverse transcriptase and cysteine-histidine-rich domains. Similar to mammalian RNAs, LINE1 RNA has a poly (A) tail at the 3'-UTR. RNA polymerase II transcribes ORF1 and ORF2 in the cytoplasm (35).

Mutations are generated during the process of evolutionary change. Proofreading polymerases repair damaged DNA sequences and eliminate potential mutations. However, some piRNAs can also mediate the activity of transposable elements (36). HP1, a chromatin-organizing protein, can affect transposon activity by regulating piRNA expression or by directly mediating the expression of transposons. We can therefore conclude that some chromatin-organizing proteins, such as HP1, act upstream or downstream of piRNAs to regulate transposons. Mutations in Aub, PIWI, and Su(var)205 are known to increase the activity of transposable elements in germline cells $(37,38)$ (Fig. 1).

\section{Epigenetic functions of specific piRNA pathway proteins}

Uncontrolled transposons threaten genomic integrity, and these alterations can be transferred to the next generation. piRNAs bind with their partner PIWI to recognize and silence transposable elements in germ cells. Both cytoplasmic and nuclear PIWI proteins target the genome to mediate transcriptional silencing. In mice, transposon inhibition by piRNAs occurs via DNA methylation at $\mathrm{CpG}$ islands in the sequences of transposable elements. During this process, the piRNA pathway mediates and maintains high levels of the repressive $\mathrm{H} 3 \mathrm{~K} 9 \mathrm{me} 3$ mark in LINE regions in germ cells. Furthermore, piRNAs recognize full-length elements of the actively transposing LINE family (39). 


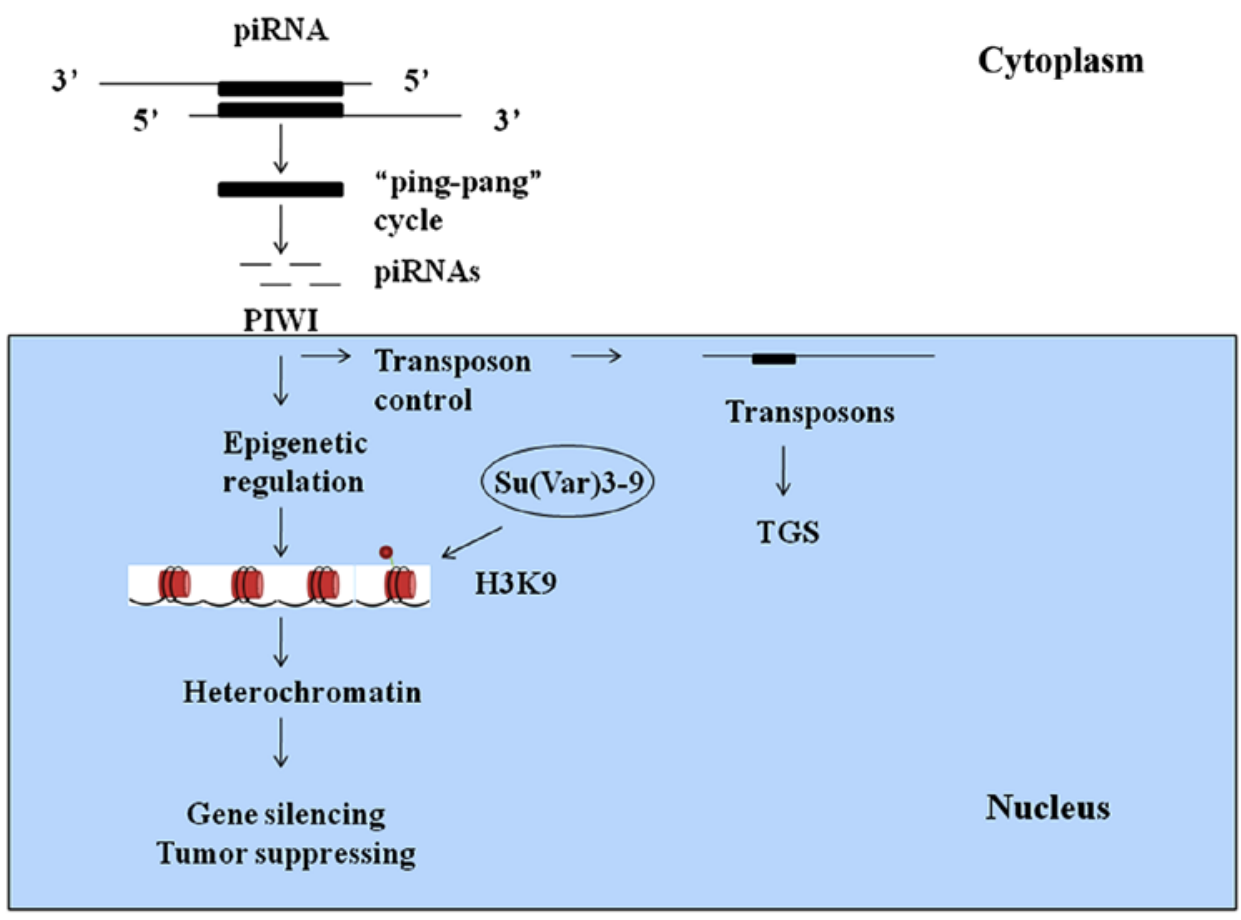

Figure 1. piRNAs bind to PIWI proteins to induce epigenetic regulation and transposon control.

Scientists recently identified two piRNA pathway proteins that are related to transposon silencing (40). The first, CG9754, is a downstream piRNA pathway factor that participates in the nuclear PIWI-piRNA complex involved in transcriptional silencing and heterochromatin formation. CG9754 is the first protein to target RNA or DNA, in heterochromatin and transcriptional silencing (41-43). PIWI is only able to silence downstream proteins if it is bound to piRNAs that are engaged with target genes (44-46). Recruitment of CG9754 directly to DNA or indirectly to RNA results in potent transcriptional silencing. Thus, CG9754 is sufficient to induce transcriptional silencing by binding to RNA. In ovarian somatic cells (OSCs), CG9754 is a downstream protein of PIWI (47-49). When vectors were used to delete CG9754, a decrease in the level of H3K9me3 was observed, and the insertion of transposable elements into transcriptional genomic regions was repressed. CG9754 mediates heterochromatin formation and integrates other cell factors, such as HP1 $\alpha$, which induces transcriptional silencing. SetDB1 is downstream of HP1 $\alpha$ and CG9754, an important HMT effector (50-52). EXD1 is the second important piRNA pathway protein. MILI slicing acts as a switch that initiates piRNA processing. Slicing activates different types of primary piRNAs in MILI and MIWI. EXD1 is a component of the PET (PIWI-EXD1-TDRD12) complex, which mediates transcriptional gene silencing (53).

\section{5. piRNAs and PIWI with cancer}

piRNAs exhibit a long lifetime in cells, even though they are only 24 to $30 \mathrm{nt}$ long (54), indicating that they are not easily degraded and may exist in cell nuclei and cytoplasm for a longer time than other RNAs (55). piRNAs play an important role in cancer development (56). Real-time PCR and next-generation sequencing analyses have made the relationship between
piRNAs and carcinogenesis increasingly clear (11). Compared with non-cancerous tissues, the expression of piR-651, piR-823, piR-4987, piR-20365, piR-20485 and piR-20583 was revealed to be altered in cancer cell lines $(12,13)$.

piRNAs can serve as biomarkers for the prognosis, diagnosis and clinical evaluation of cancer (8). The expression level of piR-823 in gastric cancer tissues was revealed to be lower than that in non-cancerous gastric tissues (57). A transfection-mediated increase in the piR-823 level inhibited the growth of gastric cancer cells. These results were also observed in nude mice. Thus, piR- 823 may be a potential marker for cancer diagnosis (58).

The expression levels of PIWIL2, PIWIL4, and piR-823 were associated with the tumor-node-metastasis (TNM) stage of renal cell carcinoma (10). Additionally, increased piR-4987 expression regulated lymph node metastasis in breast cancer.

Here, we present an example to clarify the biomarker characteristics of piRNAs. Through small RNA sequencing and real-time PCR analysis of frozen benign kidney tissues and renal cell carcinoma tissues, 26,991 piRNAs were revealed to be expressed in kidney tissues (59). In the tumor samples, 19 types of piRNAs were found to be deregulated, including 2 types that were upregulated and 17 types that were downregulated. Furthermore, differentiation was much more obvious in the metastatic renal cell carcinoma samples (16). By comparing the localized tumor samples to the metastatic samples, 46 piRNAs were found to be aberrantly expressed, 44 of which were upregulated, while only 2 were downregulated. The increased piR-32051, piR-39894, and piR-43607 are similar in length, highly homologous and derived from the same piRNA cluster on chromosome 17. Increased expression of these piRNAs is found in late-stage tumors, which means they are highly associated with renal cell carcinoma metastasis (60). 
Significantly increased piR-651 levels have been observed in non-small cell lung carcinoma (NSCLC). In A549 cells, an NSCLC cell line, piR-651 increased cell viability and metastasis. The expression of piR-651 in A549 cells decreased the proportion of cells arrested in the G0/G1 phase, thereby promoting proliferation. Oncogenes and tumor suppressor genes can be detected, and piR-651 was revealed to promote cancer growth via cyclin D1 and CDK4. These results have also been verified in lung cancer tissues from patients (61).

piR-1245 has been revealed to be overexpressed in colorectal cancer, lung, breast, stomach, bladder, kidney and prostate cancer, indicating its significant role in carcinogenesis. Poor differentiation, advanced T stage, lymph node and distant metastasis were revealed to be closely related to higher expression of piR-1245 in colorectal cancer (CRC). piR-1245 also played a crucial role in clinical pathology and revealed poor overall survival (OS) in colorectal cancer patients. piR-1245 directly targeted ATF3, BTG1, DUSP1, FAS, NFKBIA, UPP1, SESN2, TP53INP1 and MDX1 to regulate tumor progression. Thus, it may be a prognostic biomarker in CRC (62).

Similar to miRNAs, which are stable in tissues, piRNAs are relatively stable and can be used to obtain reliable results in quantitative piRNA expression studies (63). piRNAs can be detected in patient plasma (64), suggesting their potential use as biomarkers to predict TNM stage and disease prognosis (65). Furthermore, piRNAs can serve as a switch allowing tumors to proliferate and metastasize (66). Additionally, piRNAs can be indicative of patient outcomes and can be helpful in selecting effective surgical methods, radiotherapy and chemotherapy to prolong patient survival time (67).

PIWI proteins have been found in human cancers, such as breast, lung, gastric, hepatocellular, colon, renal cell carcinoma, endometrial and ovarian cancer. PIWI acts via a distinct pathway to regulate carcinogenesis. PIWIL can affect transcription, causing an increase in Bcl-XL, Stat 3 and cyclin D1 expression (68).

Cancer stem cells (CSCs), contain epigenetic alterations and signaling pathways characteristic of stem cells including self-renewal capacity, rapid proliferation and multiline age differentiation. PIWIs may be cancer testis antigens (CATs) and act as oncogenes or constitute markers for CSCs (69). Metastatic cancer cells appear to undergo epithelial-mesenchymal transition (EMT) and CSC-like phenotype (70). PIWIL2 expression was associated with altered expression of EMT markers.

As a member of the PIWI gene family, MILI binds to piRNAs and plays multiple roles in gene silencing (71) and chromatin remodeling (72). Transposon methylation has been observed in tumor cell lines and many types of human cancer (73-75). MILI was revealed to control the activity of LINE1 by methylating its $\mathrm{CpG}$ island (76). The hypomethylation of LINE1 increased the risk of cancer development and may be an indicator of cancer grade and lymph node metastasis (77,78). Wang et al found that MILI affected melanoma cell metastasis and cancer-related gene expression by regulating LINE1 methylation (79). MILI is expressed in the melanoma cell line B16 but not in the highly metastatic mouse melanoma model B16BL6. Notably, knockdown of MILI in B16 cells activated MAGEA expression and increased cell migration, whereas MILI overexpression in the B16BL6 model inhibited
MAGEA expression and decreased cell migration, yielding the opposite results $(65,80)$. Depletion of MILI/MIWI2 in mice led to reduced DNA methylation of LTR-retrotransposon promoter regions (81). Thus, LINE1 methylation by MILI was revealed to controls the expression of cancer-related genes and cell migration, and MILI plays a key role in melanoma metastasis and tumor progression.

\section{Epigenetic mechanisms of cancer metastasis related to piRNAs}

The function of piRNAs in tumors is related to transposable elements and changes in chromatin structures that are caused by epigenetic alterations, such as DNA hypomethylation (60). For example, in HeLa cells, piRNAs play an important role in inhibiting transposons by interacting with the HILI protein (82). The relationship between piRNAs and epigenetics is elaborated above, and the epigenetic changes account for a large proportion in tumors. Perhaps piRNAs and transposable elements, upstream or downstream of epigenetic alterations in tumors, affect the metastasis ability of tumors. Next, we will illustrate the epigenetic mechanisms of cancer metastasis related to piRNAs.

Cancer is a genetic and epigenetic disease (83). Cancer cells have the ability to invade tissues, enter systemic circulation, and extravasate into surrounding interstitial tissues, resulting in distant capillary retention (84). The metastasis phenotype is associated with epigenetic alterations that are involved in the cancer metastasis process. Metastasis involves cellular invasion, migration and angiogenesis of the primary carcinoma. Detection of genetic or epigenetic abnormalities can be used to identify epigenetic alterations in lesions that are morphologically normal (85). Understanding the epigenetic mechanisms of tumor metastasis related to piRNAs can assist in the identification of new tumor markers and treatments (86).

Epigenetic evaluations involve examination of DNA methylation profiles, certain RNA expression profiles (87) and histone modification profiles (88). Epigenetic alterations do not involve changes in DNA sequence (89). DNA methylation and histone modification are the major types of epigenetic alteration (90). In normal tissues, DNA methylation can prevent $X$ chromosome activation and gene mutations (91), and histone modifications can dynamically regulate gene activity.

Here, mechanisms related to epigenetic alterations are briefly summarized. First, DNA methylation not only affects the expression of individual genes but also affects DNA domains by interacting with nucleosomes, thus altering DNA packaging. DNA methylation is inevitable and occurs on the cytosine of $\mathrm{CpG}$ dinucleotides. In mammalian cells, methylation is conferred by four main DNA methyltransferases (DNMTs): DNMT1 (92), DNMT3A (93), DNMT3B $(94,95)$ and DNMT3L (96). DNMT1 adds methyl groups to hemi-methylated CpG sites, DNMT3A and DNMT3B methylate novel CpG sites, and DNMT3L interacts with DNMT3A and $3 \mathrm{~B}$ to facilitate methylation of retrotransposons. DNA demethylation and remethylation comprise a balanced process that is disrupted in cancer cells (97). Tumor progression and metastasis occur due to changes in DNA methylation. Studies investigating DNA methylation in promoter regions have been 
fruitful, leading to the discovery of adenomatous polyposis coli (APC), retinoic acid receptor $\beta-2$ and H-cadherin (98), which are also associated with tumor progression (99). In primary testicular tumors, scientists detected a gain of 5'end promoter $\mathrm{CpG}$ island methylation of the PIWIL1, PIWIL2, PIWIL4 and TDRD1 genes in association with transcriptional silencing. The DNMT3L/PIWIL2/TDRD1 complex is responsible for the loss of DNA methylation at LINE1 and IA transposons (100). The extent of DNA methylation in tumor tissues is lower than that in normal tissues, and the degree of DNA hypomethylation increases with the progression of malignancy. DNA hypomethylation is conducive to mitotic recombination, leading to chromosomal deletions and translocations, which promote chromosomal rearrangements (101). DNA methylation in malignant cells can reactivate genomic DNA repeat elements, such as long interspersed element 1 (LINE1) (77) and Alu (102). These demethylated transposons can be transcribed or transposed to other genomic regions and disrupt the genome (103). Transposable elements, which are abundant in the human genome, are highly mutagenic due to their ability to target protein-coding genes for insertion, resulting in chromosome breakage and promoting illegitimate genome rearrangement.

Another mechanism related to cancer is histone modification. There are two types of nuclear chromatin, namely, heterochromatin and euchromatin (104). In normal tissues, heterochromatin is stable during various cell cycle phases and silences during transcription (105), and the genes in euchromatin are actively transcribed. As part of an interplay with DNA methylation, facultative heterochromatin, which is associated with allelic exclusion, genomic imprinting, $\mathrm{X}$ chromosome stabilization (106), immunoglobulin (Igh/Igk) and T-cell receptor- $\alpha$ and $-\beta$ (107) gene loci, is vital for normal cell lineage development and cell differentiation via somatic methylation and inactivation of germline-specific genes (108).

Histone 3 methylation and heterochromatin. Initiation, propagation and maintenance of heterochromatin are largely controlled by trimethylation of lysine 9 on histone H3 (H3K9me3) and other synergistic epigenetic modifications (109). Chromosomal regions that are abundant in repetitive DNA help H3K9me3 stabilize constitutive heterochromatin, facultative heterochromatin and intermediate or transient heterochromatin, the 3 heterochromatin subtypes. By preventing abnormal chromosome segregation, recombination and DNA replication, $\mathrm{H} 3 \mathrm{~K} 9 \mathrm{me} 3$ regulates constitutive heterochromatin to stabilize genomic integrity (110).

Histone $\mathrm{H} 3$ determines the formation of different chromatin structures. Methylation of the N-terminal lysine of histone $\mathrm{H} 3$ is vital for well-documented histone modifications. H3K9me3, H3K36me3, and possibly H3K79me3 facilitate the opening of the chromatin configuration to form euchromatin, which is also associated with serine 10 phosphorylation and lysine 9 acetylation of histone $\mathrm{H} 3$ for active transcription of genes. H3K9me3 and H3K27me3 mainly function in the initiation, propagation and maintenance of highly compact heterochromatin to silence gene expression (111).

Histone proteins expose DNA euchromatin to facilitate the binding of transcription factors. Methylation and acetylation are the two major mechanisms by which histone function is regulated (112). Methyltransferases and demethylases modify the lysines of histone $\mathrm{H} 3$ to form mono-, di-, or tri-methylated lysines, which contribute to chromatin structure and gene transcription (113). Histone methyltransferases (HMTs) regulate histone proteins by transferring methyl groups from $\mathrm{S}$-adenosylmethionine to lysine or arginine residues in histones. Histone acetylation is regulated by histone acetyl-transferases (HATs) and deacetylases (HDACs) (114). Not surprisingly, there are other histone modifications. The balance of these modifications and their effects on histone structure ultimately coordinate DNA exposure. Histone methylation is a key event in gene transcription, and it is plausible to speculate that this type of modification can regulate DNA replication, recombination, and damage repair (115).

$\mathrm{H} 3 \mathrm{~K} 9 \mathrm{me} 3$ and transcriptional repressors. $\mathrm{H} 3 \mathrm{~K} 9 \mathrm{me} 3$ recruits transcriptional repressors such as repressor element 1 silencing transcription factor (REST) and CoREST, which contain histone deacetylases (HDACs) (116,117), H3K4me3 demethylases LSD1 (118) and Rbp4 (119), to actively transcribe gene loci, leading to gene blocking and suppression of gene transcription (120). Recruitment of DNMTs as well as additional histone methylases is responsible for localized chromatin condensation when the tethering of HP1 $\alpha$ (heterochromatin protein) and $\mathrm{HP} 13$ to $\mathrm{H} 3 \mathrm{~K} 9 \mathrm{me} 2$ or $\mathrm{H} 3 \mathrm{~K} 9 \mathrm{me} 3$ triggers gene silencing (121). Thus, $\mathrm{H} 3 \mathrm{~K} 9 \mathrm{me} 3$ acts as a natural brake to prevent unnecessary over-transcription of actively expressed genes. Attenuation of $\mathrm{H} 3 \mathrm{~K} 9 \mathrm{me} 3$ by either over-transcription of demethylases or deficiency of $\mathrm{H} 3 \mathrm{~K} 9$ methyltransferases will therefore lead to sustained expression of the genes involved in either cell cycle transition or proliferation (122).

H3K9me3 and methyltransferases in cancer. Changes in chromatin structure that are caused by epigenetic alterations can contribute to cancer development. In experimental studies using mice lacking SUV39, a methyltransferase that acts on $\mathrm{H} 3 \mathrm{~K}$ 9, enhanced genomic instability and incidence of B-cell lymphoma were observed $(123,124)$. In addition, polymorphisms of SUV39 can increase lung cancer risk due to piRNA instability and decreased levels of H3K9me3. H3K9 methyltransferases include G9a for mono- and di-methylation and SUV39h1/h2 for di- and tri-methylation of H3K9. Similarly, low levels of RIZI (125), another methyltransferase of $\mathrm{H} 3 \mathrm{~K} 9$, are frequently observed in lung cancer, breast cancer, hepatocellular carcinoma, colon cancer, neuroblastoma, and melanoma (126). Methyltransferases, such as SUV39 and RZZI act as tumor suppressors, while some demethylases may have oncogenic activity. The low expression of these methyltransferases in tumor cells may be the result of increased cell proliferation, apoptosis resistance and poor differentiation (127). Global regulation of $\mathrm{H} 3 \mathrm{~K} 9 \mathrm{me} 3$ has been observed in several human cancers, including colorectal, ovarian, and lung cancer, all of which are characterized by deficiency or elevated activity of $\mathrm{H} 3 \mathrm{~K} 9$ methyltransferases or changes in the expression of H3K9 demethylases $(128,129)$.

Other epigenetic alterations in cancer. Epigenetic changes associated with piRNA expression, affect genes associated with malignant phenotypes (VE-cadherin, VEGF-C, PAX8, 


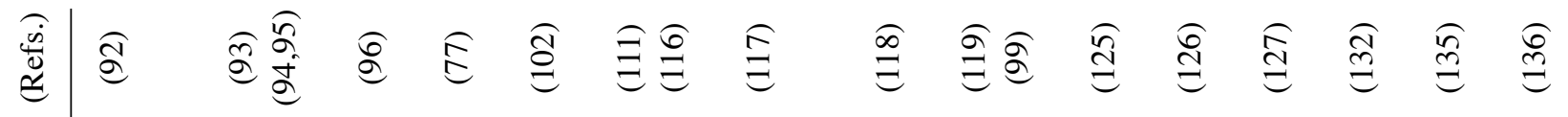

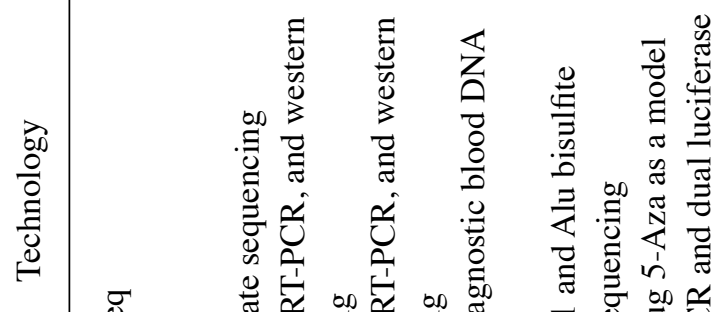

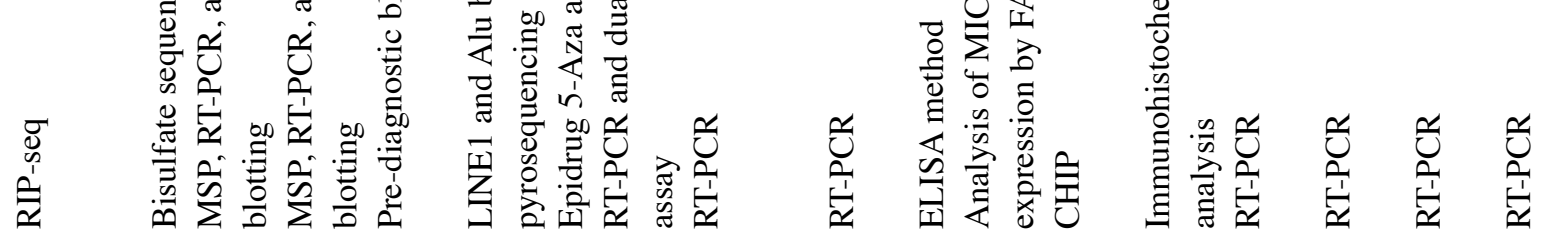

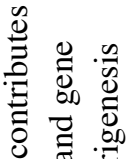

窟.

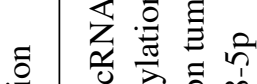

宔

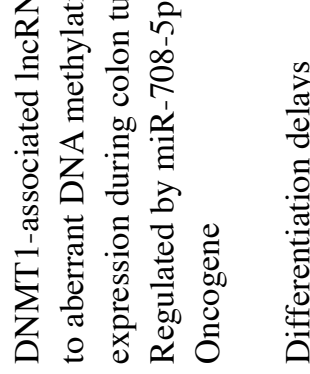

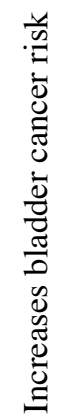

:

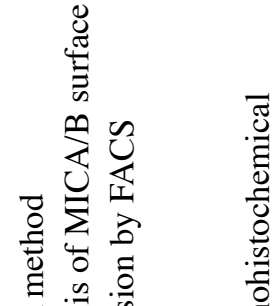

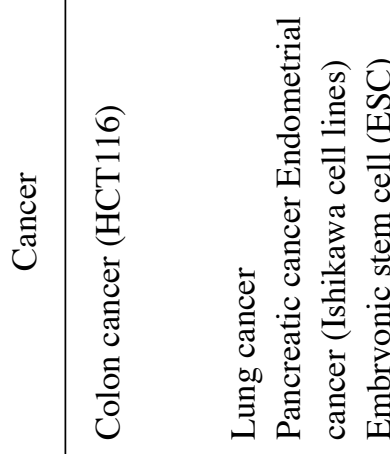

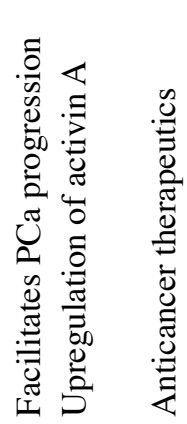

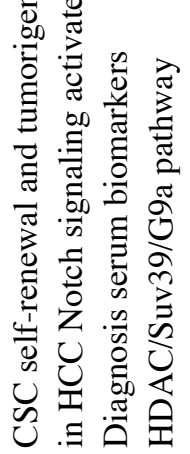

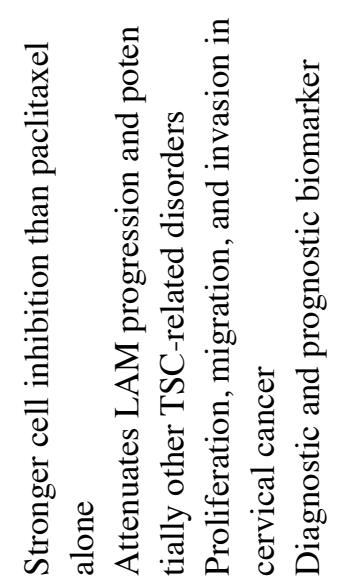

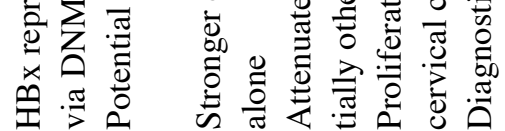

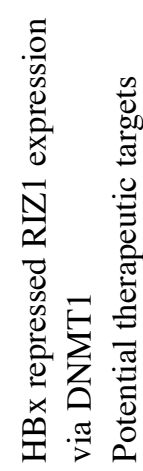<smiles>C/C=C\[13CH]C1CC1C</smiles>

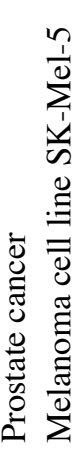

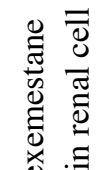
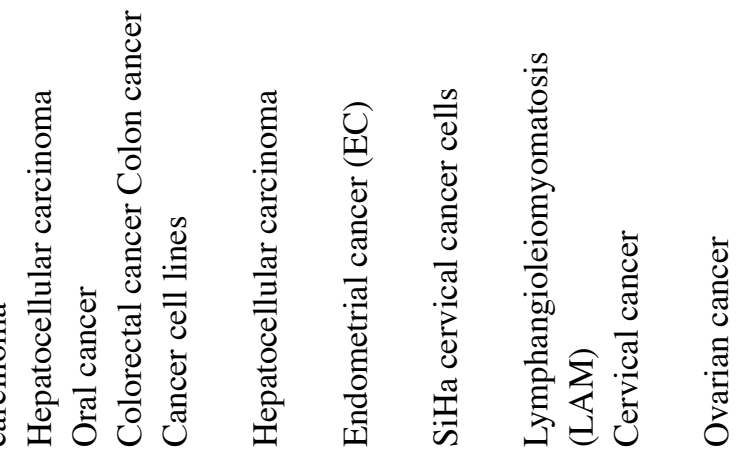<smiles>C[C@H]1C[C@@H](C)[C@@H](C)[C@@H]1C</smiles>

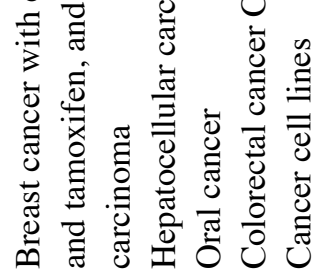

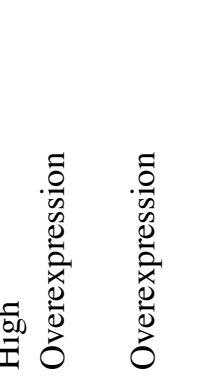

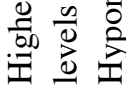

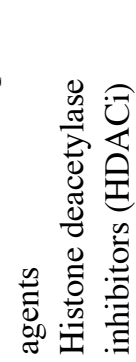

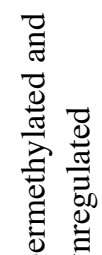

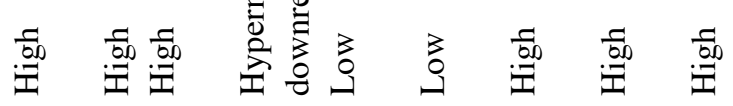
可

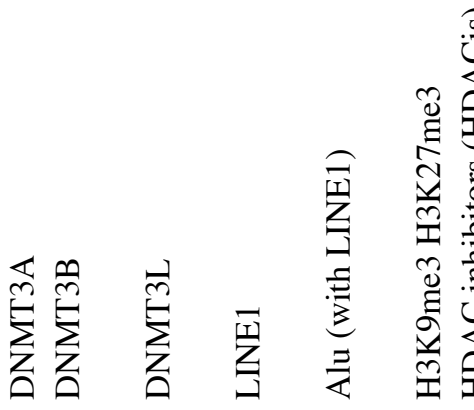

畓

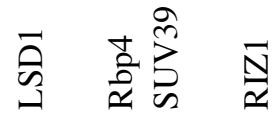

$\overleftrightarrow{S} \sum_{1}^{\Re}$ 
Keratin 7, CD13, laminin, urokinase, $\alpha 3$-integrin subunit and c-met) (8).

Detection of some forms of methylation in tumors can be diagnostic of cancer. 5-Hydroxymethylcytosine $(5 \mathrm{hmC})$ in cfDNA, which is found in blood originating from different tissues, is the basis of noninvasive prenatal diagnostic tests, organ transplant rejection diagnostics, and cancer detection. $5 \mathrm{hmC}$ is useful in gene regulation and cancer pathogenesis and can be used diagnostically to identify cancer types and track tumor stage. Li et al observed a progressive global loss of 5hmC in cfDNA in lung cancer, whereas disease-specific changes in the cell-free hydroxymethylome have been observed in hepatocellular carcinoma and pancreatic cancer (130).

In breast and prostate cancers (131), protease urokinase-type plasminogen activator [UPA (132)] was revealed to promote invasion and was associated with poor prognosis (133). Hypomethylation of the UPA promoter activates tumor genes and thus worsens patient outcomes. Carcinogenesis occurs prior to cancer metastases (134), and hypermethylation of tissue inhibitor of metalloproteinase-3 [TIMP3 (135)] was revealed to promote vascular growth and activate angiogenesis (136).

DNMT3Ab plays crucial role in directing EMT-associated metastasis in gastric cancer (GC). Increased DNMT3A expression was revealed to be closely related to a poor survival rate in GC, breast, lung and liver cancer. Furthermore, TNM stage and lymph node metastasis of GC cells were more closely associated with DNMT3A than with DNMT1 and DNMT3B. Increased expression of DNMT3Ab was demonstrated to promote GC cell migration and invasion as well as EMT progression. DNMT3Ab mediated the E-cadherin gene via DNA hypermethylation and histone modifications of H3K9me2 and H3K27me3. DNMT3Ab effectively regulated the expression of E-cadherin via DNA hypermethylation and histone modifications of $\mathrm{H} 3 \mathrm{~K} 9 \mathrm{me} 2$ and $\mathrm{H} 3 \mathrm{~K} 27 \mathrm{me} 3$. DNMT3Ab in cooperation with $\mathrm{H} 3 \mathrm{~K} 9 \mathrm{me} 2$ and H3K27me3 contributed to the transcriptional regulation of E-cadherin in a Snail-dependent manner and multiple metastasis-associated genes and oncogenic signaling pathways are regulated by DNMT3Ab overexpression. Thus, it was revealed that DNMT3Ab acts as a crucial regulator of metastasis-related genes in GC (137) (Table I).

Gliomas with histone H3 lysine27-to-methionine mutations primarily occur in the central nervous system of young children, which means that there is a link between genetics and cellular context in tumorigenesis. Through single-cell RNA sequencing of 3321 cells from six primary H3K27M-glioma and matched models, Filbin et al found that H3K27M-gliomas contained cells that resembled oligodendrocyte precursor cells (OPC-like cells). OPC-like cells tend to exhibit higher proliferation and a greater tumor-propagating potential and some of these cells display PDGFRA signaling (138).

\section{Epigenetics of ncRNAs in cancer}

EMT and angiogenesis are regulated by miRNAs $(139,140)$. miRNAs function in cell differentiation, proliferation, apoptosis and serve as tumor suppressors and tumor promoters. Additionally, miRNAs can control other genes in certain protein pathways. If the expression of certain miRNAs can be inhibited, cancer growth or cancer metastasis may be suppressed. For example, transfection of breast cancer cells with vectors inhibiting miRNA-155 was revealed to reduce the level of CXCR4. The transfected cells exhibited lower migration and invasion rates in vitro and resulted in fewer lung metastases in vivo than control cells (141).

miRNAs, short interfering RNAs (siRNAs) and piRNAs are involved in the regulation of mRNA transcripts, chromatin-mediated gene silencing, and DNA rearrangement. miRNAs accelerate de-adenylation of the poly(A) tail and downregulate the expression of some pathways, thereby downregulating the expression of hundreds of target genes. siRNAs can also control transposons. RDR2-dependent siRNAs, which are endo-siRNAs, silence transposons, retroelements and DNA methylation (142). siRNAs bind to a nascent RNA being transcribed at their target site, resulting in RNA-induced transcriptional silencing (RITS) and formation of the RNA-directed RNA polymerase complex (RDRC) at the site of intended heterochromatin formation, which in turn results in TGS. TGS occurs in the nucleus. During this process, siRNAs guide miRNAs to modify chromatin, which also influences the cell cycle (143). miR-127 and miR-136 are released near $2 \mathrm{CpG}$ islands in the Rtl1 transcript and thus regulate RISC-mediated cleavage of the maternal transcript, resulting in late-fetal or neonatal lethality (144).

miRNAs are the best studied ncRNAs (145). miRNAs play a critical role in regulating the maintenance and behavior of stem cells during self-renewal and differentiation. miR-290 serves as a transcriptional repressor of DNMTs (146). DNMTs can epigenetically silence OCT4, a transcription factor in ES cells, which can renew and differentiate into other cell types (147).

In mice, the miR-290-295 miRNA cluster was revealed to act as a transcriptional repressor of the DNMTs, Dnmt3a and Dnmt3b, resulting in the appearance of long telomeres and increased telomere recombination. The expression of this cluster remained high in undifferentiated ES cells, but decreased after ES cell differentiation. This example indicates a direct or indirect function of miRNAs in regulating genes involved in self-renewal or differentiation by affecting methylation.

\section{Discussion}

piRNA expression detected in both patient lymph nodes and serum samples is related to tumor treatment failure. piRNAs can act as tumor promoters or cancer suppressors and can participate in other carcinoma cell activities. piRNAs and PIWI can serve as biomarkers for the prognosis, diagnosis and clinical evaluation of cancer, and can be helpful in selecting effective surgical methods, radiotherapy and chemotherapy to prolong patient survival time. piRNA can serve as a switch, allowing tumors to proliferate and metastasize.

In mammals, PIWI proteins function as transposoninhibiting factors through TGS. PIWI acts via a distinct pathway to regulate carcinogenesis by affecting transcription and the expression of other carcinoma-related genes that reduce apoptosis and increase cell proliferation and transformation. Transcriptional silencing, heterochromatin formation, transgene silencing, HP1 $\alpha$ alteration, histone modifications and transposon suppression are all associated 
with PIWI, piRNAs and the piRNA pathway. Transposable elements are classified as either retrotransposons or DNA transposons. Retrotransposons can be further divided into LTR and non-LTR groups. Non-LTRs are divided into the autonomous non-LTRs LINEs and non-autonomous LTRs SINEs. Chromatin-organizing proteins such as HP1, Aub and $\mathrm{Su}(\mathrm{var}) 205$, act upstream or downstream of piRNAs to regulate transposons. Hypomethylation of LINE1 increases the risk of cancer development and may be an indicator of cancer grade and lymph node metastasis. LINE1 methylation by MILI was revealed to control the expression of cancer-related genes and cell migration, and MILI played a key role in melanoma metastasis and tumor progression. In the sequences of transposable elements, the piRNA pathway mediates and maintains high levels of the repressive $\mathrm{H} 3 \mathrm{~K} 9$ me 3 mark in LINE1 regions in germ cells. There are two identified pathway proteins that are related to transposon silencing: CG9754 and EXD1.

Perhaps piRNAs, PIWI, transposable elements and piRNA pathways, upstream or downstream of the epigenetic alterations in tumors, affect the metastasis ability of tumors. In addition, epigenetic alteration of piRNAs, cancer stem cells, CpG island methylation and EMT all participate in cancer metastasis.

Epigenetic alterations associated with cancer metastasis involve DNA methylation, histone modification and certain RNA expression profiles. First, DNA methylation affects the expression of individual genes and DNA domains. The degree of DNA hypomethylation increases as tumors progress and metastasize. DNA methylation and histone modification can activate genomic DNA repeat elements, such as LINE1 and Alu, which can be transcribed or transposed to other genomic regions and disrupt the genome, resulting in chromosome breakage and illegitimate genome rearrangement.

$\mathrm{H} 3 \mathrm{~K} 9 \mathrm{me} 3$ and other synergistic epigenetic modifications control heterochromatin, but in tumors, that balance has been disrupted. Therefore, with the ability to stabilize genomic integrity by preventing abnormal chromosome segregation, recombination and DNA replication, $\mathrm{H} 3 \mathrm{~K} 9 \mathrm{me} 3$ and H3K27me3 mainly function in the initiation, propagation and maintenance of highly compact heterochromatin to silence gene expression. Methylation and acetylation are the two major mechanisms that regulate histone function. HMTs regulate histone proteins. Histone acetylation is regulated by HATs and HDACs. Several HMTs exhibit tumor suppressor functions, and some demethylases exhibit oncogenic activity. H3K9me3 recruits transcriptional repressors such as REST and CoREST. The low expression of methyltransferases such as SUV39 and RZZI in tumor cells may be the result of increased cell proliferation and apoptosis resistance and poor differentiation. Global regulation of $\mathrm{H} 3 \mathrm{~K} 9 \mathrm{me} 3$ has been observed in several human cancers, including colorectal, ovarian and lung cancer, all of which are characterized by deficiency or elevated activity of $\mathrm{H} 3 \mathrm{~K} 9$ methyltransferases or altered expression of $\mathrm{H} 3 \mathrm{~K} 9$ demethylases. $5 \mathrm{hmC}$ can be used to identify cancer type and track tumor stage. DNMT3Ab cooperated with $\mathrm{H} 3 \mathrm{~K} 9 \mathrm{me} 2$ and H3K27me3 played a crucial role in directing EMT-associated metastasis in gastric cancer.

Understanding the epigenetic mechanisms of tumor metastasis related to piRNAs can assist in the identification of new tumor markers and treatments. piRNAs can be indicative of patient outcomes and can be helpful in selecting effective surgical methods, radiotherapy and chemotherapy to prolong patient survival time. piRNAs can be used as biomarkers to predict TNM stage and disease prognosis. Since preventing tumor metastasis is still a formidable problem, studies on the potential of piRNAs and epigenetic alternations for diagnosis and prediction of clinical cancer stages are greatly needed.

\section{Acknowledgements}

Not applicable.

\section{Funding}

The present review was supported by the grant 2017Y001 from the First Affiliated Hospital of Harbin Medical University Research Innovation Fund. This review was supported by the First Affiliated Hospital of Harbin Medical University and the Laboratory of Hepatosplenic Surgery Center of Heilongjiang Province. The authors are solely responsible for the content, and this manuscript does not represent the official views of the First Affiliated Hospital of Harbin Medical University.

\section{Availability of data and materials}

Not applicable.

\section{Author's contributions}

$\mathrm{BC}, \mathrm{SZ}$ and JL conceived and designed the study. JL wrote the manuscript. SZ prepared the figure and the table. $\mathrm{BC}$ wrote the ncRNA part, reviewed and edited the manuscript. All authors read and approved the manuscript and agree to be accountable for all aspects of the research in ensuring that the accuracy or integrity of any part of the work are appropriately investigated and resolved.

\section{Ethics approval and consent to participate}

Not applicable.

\section{Patient consent for publication}

Not applicable.

\section{Competing interests}

The authors declare that they have no competing interests.

\section{References}

1. Li C, Vagin VV, Lee S, Xu J, Ma S, Xi H, Seitz H, Horwich MD, Syrzycka M, Honda BM, et al: Collapse of germline piRNAs in the absence of Argonaute 3 reveals somatic piRNAs in flies. Cell 137: 509-521, 2009.

2. Shrey K, Suchit A, Nishant M and Vibha R: RNA interference: Emerging diagnostics and therapeutics tool. Biochem Biophys Res Commun 386: 273-277, 2009.

3. Collins LJ and Penny D: The RNA infrastructure: Dark matter of the eukaryotic cell? Trends Genet 25: 120-128, 2009.

4. Malone CD and Hannon GJ: Small RNAs as guardians of the genome. Cell 136: 656-668, 2009. 
5. Malone CD, Brennecke J, Dus M, Stark A, McCombie WR, Sachidanandam R and Hannon GJ: Specialized piRNA pathways act in germline and somatic tissues of the Drosophila ovary. Cell 137: 522-535, 2009.

6. Freedman JE, Gerstein M, Mick E, Rozowsky J, Levy D, Kitchen R, Das S, Shah R, Danielson K, Beaulieu L, et al: Diverse human extracellular RNAs are widely detected in human plasma Nat Commun 7: 11106, 2016.

7. Iliev R, Stanik M, Fedorko M, Poprach A, VychytilovaFaltejskova P, Slaba K, Svoboda M, Fabian P, Pacik D, Dolezel J, et al: Decreased expression levels of PIWIL1, PIWIL2, and PIWIL4 are associated with worse survival in renal cell carcinoma patients. OncoTargets Ther 9: 217-222, 2016.

8. Lee JH, Schutte D, Wulf G, Füzesi L, Radzun HJ, Schweyer S, Engel W and Nayernia K: Stem-cell protein Piwil2 is widely expressed in tumors and inhibits apoptosis through activation of Stat3/Bcl-XL pathway. Hum Mol Genet 15: 201-211, 2006.

9. Taubert H, Greither T, Kaushal D, Würl P, Bache M, Bartel F, Kehlen A, Lautenschläger C, Harris L, Kraemer K, et al: Expression of the stem cell self-renewal gene Hiwi and risk of tumour-related death in patients with soft-tissue sarcoma. Oncogene 26: 1098-1100, 2007.

10. Wang Y, Liu Y, Shen X, Zhang X, Chen X, Yang C and Gao H: The PIWI protein acts as a predictive marker for human gastric cancer. Int J Clin Exp Pathol 5: 315-325, 2012.

11. Cheng J, Guo JM, Xiao BX, Miao Y, Jiang Z, Zhou H and Li QN piRNA, the new non-coding RNA, is aberrantly expressed in human cancer cells. Clin Chim Acta 412: 1621-1625, 2011.

12. Huang G, Hu H, Xue X, Shen S, Gao E, Guo G, Shen X and Zhang X: Altered expression of piRNAs and their relation with clinicopathologic features of breast cancer. Clin Transl Oncol 15: 563-568, 2013 .

13. Law PT, Qin H, Ching AK, Lai KP, Co NN, He M, Lung RW, Chan AW, Chan TF and Wong N: Deep sequencing of small RNA transcriptome reveals novel non-coding RNAs in hepatocellular carcinoma. J Hepatol 58: 1165-1173, 2013.

14. Yan H, Wu QL, Sun CY, Ai LS, Deng J, Zhang L, Chen L, Chu ZB Tang B, Wang K, et al: piRNA-823 contributes to tumorigenesis by regulating de novo DNA methylation and angiogenesis in multiple myeloma. Leukemia 29: 196-206, 2015.

15. Luteijn MJ and Ketting RF: PIWI-interacting RNAs: From generation to transgenerational epigenetics. Nat Rev Genet 14: 523-534, 2013

16. Li Y, Wu X, Gao H, Jin JM, Li AX, Kim YS, Pal SK, Nelson RA, Lau CM, Guo C, et al: Piwi-Interacting RNAs (piRNAs) are dysregulated in renal cell carcinoma and associated with tumor metastasis and cancer-specific survival. Mol Med 21: 381-388, 2015.

17. Gigek CO, Chen ES, Calcagno DQ, Wisnieski F, Burbano RR and Smith MA: Epigenetic mechanisms in gastric cancer. Epigenomics 4: 279-294, 2012.

18. Potter VR: Initiation and promotion in cancer formation: The importance of studies on intercellular communication. Yale J Biol Med 53: 367-384, 1980.

19. Lujambio A, Calin GA, Villanueva A, Ropero S, SánchezCéspedes M, Blanco D, Montuenga LM, Rossi S, Nicoloso MS Faller WJ, et al: A microRNA DNA methylation signature for human cancer metastasis. Proc Natl Acad Sci USA 105 $13556-13561,2008$.

20. Tiwari VK, McGarvey KM, Licchesi JD, Ohm JE, Herman JG, Schübeler D and Baylin SB: PcG proteins, DNA methylation, and gene repression by chromatin looping. PLoS Biol 6: 2911-2927, 2008.

21. Nowacka-Zawisza M and Wisnik E: DNA methylation and histone modifications as epigenetic regulation in prostate cancer (Review). Oncol Rep 38: 2587-2596, 2017.

22. Weick EM and Miska EA: piRNAs: From biogenesis to function Development 141: 3458-3471, 2014.

23. Han BW and Zamore PD: piRNAs. Curr Biol 24: R730-R733, 2014.

24. Aravin AA, Sachidanandam R, Girard A, Fejes-Toth K and Hannon GJ: Developmentally regulated piRNA clusters implicate MILI in transposon control. Science 316: 744-747, 2007.

25. Ross RJ, Weiner MM and Lin H: PIWI proteins and PIWI-interacting RNAs in the soma. Nature 505: 353-359, 2014.

26. Houwing S, Kamminga LM, Berezikov E, Cronembold D, Girard A, van den Elst H, Filippov DV, Blaser H, Raz E, Moens CB, et al: A role for Piwi and piRNAs in germ cell maintenance and transposon silencing in Zebrafish. Cell 129: 69-82, 2007.
27. Aravin AA, Sachidanandam R, Bourc'his D, Schaefer C, Pezic D, Toth KF, Bestor T and Hannon GJ: A piRNA pathway primed by individual transposons is linked to de novo DNA methylation in mice. Mol Cell 31: 785-799, 2008.

28. Ghildiyal $M$ and Zamore PD: Small silencing RNAs: An expanding universe. Nat Rev Genet 10: 94-108, 2009.

29. Peng JC and Lin H: Beyond transposons: The epigenetic and somatic functions of the Piwi-piRNA mechanism. Curr Opin Cell Biol 25: 190-194, 2013.

30. Feschotte $C$ and Pritham EJ: DNA transposons and the evolution of eukaryotic genomes. Annu Rev Genet 41: 331-368, 2007.

31. Kubo S, Seleme MC, Soifer HS, Perez JL, Moran JV, Kazazian HH Jr and Kasahara N: L1 retrotransposition in nondividing and primary human somatic cells. Proc Natl Acad Sci USA 103: 8036-8041, 2006

32. Pelisson A, Mejlumian L, Robert V, Terzian C and Bucheton A: Drosophila germline invasion by the endogenous retrovirus gypsy: Involvement of the viral env gene. Insect Biochem Mol Biol 32: 1249-1256, 2002

33. Leblanc P, Desset S, Giorgi F, Taddei AR, Fausto AM, Mazzini M, Dastugue B and Vaury C: Life cycle of an endogenous retrovirus, ZAM, in Drosophila melanogaster. J Virol 74: 10658-10669, 2000.

34. Brouha B, Schustak J, Badge RM, Lutz-Prigge S, Farley AH, Moran JV and Kazazian HH Jr: Hot L1s account for the bulk of retrotransposition in the human population. Proc Natl Acad Sci USA 100: 5280-5285, 2003

35. Alisch RS, Garcia-Perez JL, Muotri AR, Gage FH and Moran JV Unconventional translation of mammalian LINE-1 retrotransposons. Genes Dev 20: 210-224, 2006.

36. Baer CF, Miyamoto MM and Denver DR: Mutation rate variation in multicellular eukaryotes: Causes and consequences. $\mathrm{Na} \mathrm{Rev}$ Genet 8: 619-631, 2007.

37. Belinco C, Diprima SN, Wolff RE, Thorp MW, Buschette JT and Simmons MJ: Cytotype regulation in Drosophila melanogaster: Synergism between telomeric and non-telomeric P elements. Genet Res 91: 383-394, 2009.

38. Simmons MJ, Peterson MP, Thorp MW, Buschette JT, DiPrima SN, Harter CL and Skolnick MJ: piRNA-mediated transposon regulation and the germ-line mutation rate in Drosophila melanogaster males. Mutat Res 773: 16-21, 2015.

39. Pezic D, Manakov SA, Sachidanandam R and Aravin AA: piRNA pathway targets active LINE1 elements to establish the repressive H3K9me3 mark in germ cells. Genes Dev 28: 1410-1428, 2014.

40. Czech B, Preall JB, McGinn J and Hannon GJ: A transcriptome-wide RNAi screen in the Drosophila ovary reveals factors of the germline piRNA pathway. Mol Cell 50: 749-761, 2013.

41. Handler D, Meixner K, Pizka M, Lauss K, Schmied C, Gruber FS and Brennecke J: The genetic makeup of the Drosophila piRNA pathway. Mol Cell 50: 762-777, 2013

42. Muerdter F, Guzzardo PM, Gillis J, Luo Y, Yu Y, Chen C, Fekete R and Hannon GJ: A genome-wide RNAi screen draws a genetic framework for transposon control and primary piRNA biogenesis in Drosophila. Mol Cell 50: 736-748, 2013.

43. Sarot E, Payen-Groschene G, Bucheton A and Pelisson A Evidence for a piwi-dependent RNA silencing of the gypsy endogenous retrovirus by the Drosophila melanogaster flamenco gene. Genetics 166: 1313-1321, 2004.

44. Le Thomas A, Rogers AK, Webster A, Marinov GK, Liao SE, Perkins EM, Hur JK, Aravin AA and Tóth KF: Piwi induces piRNA-guided transcriptional silencing and establishment of a repressive chromatin state. Genes Dev 27: 390-399, 2013.

45. Sienski G, Batki J, Senti KA, Dönertas D, Tirian L, Meixner K and Brennecke J: Silencio/CG9754 connects the Piwi-piRNA complex to the cellular heterochromatin machinery. Genes Dev 29: 2258-2271,2015.

46. Sienski G, Donertas D and Brennecke J: Transcriptional silencing of transposons by Piwi and maelstrom and its impact on chromatin state and gene expression. Cell 151: 964-980, 2012.

47. Gunawardane LS, Saito K, Nishida KM, Miyoshi K, Kawamura Y, Nagami T, Siomi H and Siomi MC: A slicer-mediated mechanism for repeat-associated siRNA 5'end formation in Drosophila. Science 315: 1587-1590, 2007.

48. Niki Y, Yamaguchi T and Mahowald AP: Establishment of stable cell lines of Drosophila germ-line stem cells. Proc Natl Acad Sci USA 103: 16325-16330, 2006

49. Saito K, Ishizu H, Komai M, Kotani H, Kawamura Y, Nishida KM, Siomi H and Siomi MC: Roles for the Yb body components Armitage and $\mathrm{Yb}$ in primary piRNA biogenesis in Drosophila. Genes Dev 24: 2493-2498, 2010. 
50. Ayyanathan K, Lechner MS, Bell P, Maul GG, Schultz DC, Yamada Y, Tanaka K, Torigoe K and Rauscher FJ III: Regulated recruitment of HP1 to a euchromatic gene induces mitotically heritable, epigenetic gene silencing: A mammalian cell culture model of gene variegation. Genes Dev 17: 1855-1869, 2003.

51. Li Y, Danzer JR, Alvarez P, Belmont AS and Wallrath LL: Effects of tethering HP1 to euchromatic regions of the Drosophila genome. Development 130: 1817-1824, 2003.

52. Rangan P, Malone CD, Navarro C, Newbold SP, Hayes PS, Sachidanandam R, Hannon GJ and Lehmann R: piRNA production requires heterochromatin formation in Drosophila. Curr Biol 21: 1373-1379, 2011.

53. Yang Z, Chen KM, Pandey RR, Homolka D, Reuter M, Janeiro BK, Sachidanandam R, Fauvarque MO, McCarthy AA and Pillai RS: PIWI slicing and EXD1 drive biogenesis of nuclear piRNAs from cytosolic targets of the mouse piRNA pathway. Mol Cell 61: 138-152, 2016.

54. He W, Wang Z, Wang Q, Fan Q, Shou C, Wang J, Giercksky KE, Nesland JM and Suo Z: Expression of HIWI in human esophageal squamous cell carcinoma is significantly associated with poorer prognosis. BMC Cancer 9: 426, 2009.

55. He G, Chen L, Ye Y, Xiao Y, Hua K, Jarjoura D, Nakano T, Barsky SH, Shen R and Gao JX: Piwil2 expressed in various stages of cervical neoplasia is a potential complementary marker for p16 $6^{\mathrm{INK} 4 \mathrm{a}}$. Am J Transl Res 2: 156-169, 2010.

56. Rajasethupathy P, Antonov I, Sheridan R, Frey S, Sander C, Tuschl T and Kandel ER: A role for neuronal piRNAs in the epigenetic control of memory-related synaptic plasticity. Cell 149: 693-707, 2012

57. Cui L, Lou Y, Zhang X, Zhou H, Deng H, Song H, Yu X, Xiao B, Wang W and Guo J: Detection of circulating tumor cells in peripheral blood from patients with gastric cancer using piRNAs as markers. Clin Biochem 44: 1050-1057, 2011.

58. Cheng J, Deng H, Xiao B, Zhou H, Zhou F, Shen Z and Guo J: piR-823, a novel non-coding small RNA, demonstrates in vitro and in vivo tumor suppressive activity in human gastric cancer cells. Cancer Lett 315: 12-17, 2012.

59. Gupta K, Miller JD, Li JZ, Russell MW and Charbonneau C: Epidemiologic and socioeconomic burden of metastatic renal cell carcinoma (mRCC): A literature review. Cancer Treat Rev 34: 193-205, 2008.

60. Siomi MC, Sato K, Pezic D and Aravin AA: PIWI-interacting small RNAs: The vanguard of genome defence. Nat Rev Mol Cell Biol 12: 246-258, 2011.

61. Li D, Luo Y, Gao Y, Yang Y, Wang Y, Xu Y, Tan S, Zhang Y, Duan $J$ and Yang Y: piR-651 promotes tumor formation in non-small cell lung carcinoma through the upregulation of cyclin D1 and CDK4. Int J Mol Med 38: 927-936, 2016.

62. Weng W, Liu N, Toiyama Y, Kusunoki M, Nagasaka T, Fujiwara T, Wei Q, Qin H, Lin H, Ma Y and Goel A: Novel evidence for a PIWI-interacting RNA (piRNA) as an oncogenic mediator of disease progression, and a potential prognostic biomarker in colorectal cancer. Mol Cancer 17: 16, 2018.

63. Wu X, Weng L, Li X, Guo C, Pal SK, Jin JM, Li Y, Nelson RA, $\mathrm{Mu} \mathrm{B}$, Onami SH, et al: Identification of a 4-microRNA signature for clear cell renal cell carcinoma metastasis and prognosis. PLoS One 7: e35661, 2012.

64. Zeng Y, Qu LK, Meng L, Liu CY, Dong B, Xing XF, Wu J and Shou CC: HIWI expression profile in cancer cells and its prognostic value for patients with colorectal cancer. Chin Med J 124: 2144-2149, 2011.

65. Liu JJ, Shen R, Chen L, Ye Y, He G, Hua K, Jarjoura D, Nakano T, Ramesh GK, Shapiro CL, et al: Piwil2 is expressed in various stages of breast cancers and has the potential to be used as a novel biomarker. Int J Clin Exp Pathol 3: 328-337, 2010.

66. Grochola LF, Greither T, Taubert H, Möller P, Knippschild U, Udelnow A, Henne-Bruns D and Würl P: The stem cell-associated Hiwi gene in human adenocarcinoma of the pancreas: Expression and risk of tumour-related death. Br J Cancer 99: 1083-1088, 2008.

67. Mei Y, Clark D and Mao L: Novel dimensions of piRNAs in cancer. Cancer Lett 336: 46-52, 2013.

68. Tan Y, Liu L, Liao M, Zhang C, Hu S, Zou M, Gu M and Li X: Emerging roles for PIWI proteins in cancer. Acta Biochim Biophys Sin 47: 315-324, 2015.

69. Litwin M, Szczepanska-Buda A, Piotrowska A, Dziegiel P and Witkiewicz W: The meaning of PIWI proteins in cancer development. Oncol Lett 13: 3354-3362, 2017.
70. Tamura S, Isobe T, Ariyama H, Nakano M, Kikushige $\mathrm{Y}$, Takaishi S, Kusaba H, Takenaka K, Ueki T, Nakamura M, et al: Ecadherin regulates proliferation of colorectal cancer stem cells through NANOG. Oncol Rep 40: 693-703, 2018.

71. Liu J, Carmell MA, Rivas FV, Marsden CG, Thomson JM, Song JJ, Hammond SM, Joshua-Tor L and Hannon GJ: Argonaute 2 is the catalytic engine of mammalian RNAi. Science 305: 1437-1441, 2004.

72. Yin $\mathrm{H}$ and Lin $\mathrm{H}$ : An epigenetic activation role of Piwi and a Piwi-associated piRNA in Drosophila melanogaster. Nature 450: 304-308, 2007.

73. Chen Y, Hu W, Lu Y, Jiang S, Li C, Chen J, Tao D, Liu Y, Yang Y and Ma Y: A TALEN-based specific transcript knock-down of PIWIL2 suppresses cell growth in HepG2 tumor cell. Cell Pprolif 47: 448-456, 2014.

74. Lee JH, Jung C, Javadian-Elyaderani P, Schweyer S, Schütte D, Shoukier M, Karimi-Busheri F, Weinfeld M, Rasouli-Nia A, Hengstler JG, et al: Pathways of proliferation and antiapoptosis driven in breast cancer stem cells by stem cell protein piwil2. Cancer Res 70: 4569-4579, 2010.

75. Zhang H, Ren Y, Xu H, Pang D, Duan C and Liu C: The expression of stem cell protein Piwil2 and piR-932 in breast cancer. Surg Oncol 22: 217-223, 2013.

76. Lee E, Iskow R, Yang L, Gokcumen O, Haseley P, Luquette LJ III, Lohr JG, Harris CC, Ding L, Wilson RK, et al: Landscape of somatic retrotransposition in human cancers. Science 337: 967-971, 2012.

77. Andreotti G, Karami S, Pfeiffer RM, Hurwitz L, Liao LM, Weinstein SJ, Albanes D, Virtamo J, Silverman DT, Rothman N and Moore LE: LINE1 methylation levels associated with increased bladder cancer risk in pre-diagnostic blood DNA among US (PLCO) and European (ATBC) cohort study participants. Epigenetics 9: 404-415, 2014.

78. Daskalos A, Nikolaidis G, Xinarianos G, Savvari P, Cassidy A, Zakopoulou R, Kotsinas A, Gorgoulis V, Field JK and Liloglou T: Hypomethylation of retrotransposable elements correlates with genomic instability in non-small cell lung cancer. Int $\mathbf{J}$ Cancer 124: 81-87, 2009.

79. Wang X, Jiang C, Fu B, Zhu R, Diao F, Xu N, Chen Z, Tao W and Li CJ: MILI, a PIWI family protein, inhibits melanoma cell migration through methylation of LINE1. Biochem Biophys Res Commun 457: 514-519, 2015

80. Ye Y, Yin DT, Chen L, Zhou Q, Shen R, He G, Yan Q, Tong Z, Issekutz AC, Shapiro CL, et al: Identification of Piwil2-like (PL2L) proteins that promote tumorigenesis. PLoS One 5: e13406, 2010.

81. Kuramochi-Miyagawa S, Watanabe T, Gotoh K, Totoki Y, Toyoda A, Ikawa M, Asada N, Kojima K, Yamaguchi Y, Ijiri TW, et al: DNA methylation of retrotransposon genes is regulated by Piwi family members MILI and MIWI2 in murine fetal testes. Genes Dev 22: 908-917, 2008.

82. Lu Y, Li C, Zhang K, Sun H, Tao D, Liu Y, Zhang S and Ma Y: Identification of piRNAs in Hela cells by massive parallel sequencing. BMB Rep 43: 635-641, 2010.

83. Virani S, Colacino JA, Kim JH and Rozek LS: Cancer epigenetics: A brief review. ILAR J 53: 359-369, 2012.

84. Chik F, Szyf M and Rabbani SA: Role of epigenetics in cancer initiation and progression. Adv Exp Med Biol 720: 91-104, 2011.

85. Cavalli LR, Urban CA, Dai D, de Assis S, Tavares DC, Rone JD, Bleggi-Torres LF, Lima RS, Cavalli IJ, Issa JP, et al: Genetic and epigenetic alterations in sentinel lymph nodes metastatic lesions compared to their corresponding primary breast tumors. Cancer Genet Cytogenet 146: 33-40, 2003.

86. Hanahan D and Weinberg RA: Hallmarks of cancer: The next generation. Cell 144: 646-674, 2011

87. Calin GA and Croce CM: MicroRNA signatures in human cancers. Nat Rev Cancer 6: 857-866, 2006.

88. Esteller M: Cancer epigenomics: DNA methylomes and histone-modification maps. Nat Rev Genet 8: 286-298, 2007.

89. Hinoue T, Weisenberger DJ, Lange CP, Shen H, Byun HM, Van Den Berg D, Malik S, Pan F, Noushmehr H, van Dijk CM, et al: Genome-scale analysis of aberrant DNA methylation in colorectal cancer. Genome Res 22: 271-282, 2012.

90. Azad N, Zahnow CA, Rudin CM and Baylin SB: The future of epigenetic therapy in solid tumours-lessons from the past. Nat Rev Clin Oncol 10: 256-266, 2013.

91. Jones PA and Taylor SM: Cellular differentiation, cytidine analogs and DNA methylation. Cell 20: 85-93, 1980. 
92. Merry CR, Forrest ME, Sabers JN, Beard L, Gao XH, Hatzoglou M, Jackson MW, Wang Z, Markowitz SD and Khalil AM: DNMT1-associated long non-coding RNAs regulate global gene expression and DNA methylation in colon cancer. Hum Mol Genet 24: 6240-6253, 2015.

93. Liu T, Wu X, Chen T, Luo Z and Hu X: Downregulation of DNMT3A by miR-708-5p inhibits lung cancer stem cell-like phenotypes through repressing Wnt/ $\beta$-catenin signaling. Clin Cancer Res 24: 1748-1760, 2017.

94. Wang LH, Huang J, Wu CR, Huang LY, Cui J, Xing ZZ and Zhao CY: Downregulation of miR29b targets DNMT3b to suppress cellular apoptosis and enhance proliferation in pancreatic cancer. Mol Med Rep 17: 2113-2120, 2018.

95. Yang L, Hou J, Cui XH, Suo LN and Lv YW: RG108 induces the apoptosis of endometrial cancer Ishikawa cell lines by inhibiting the expression of DNMT3B and demethylation of HMLH1. Eur Rev Med Pharmacol Sci 21: 5056-5064, 2017.

96. Heo J, Lim J, Lee S, Jeong J, Kang H, Kim Y, Kang JW, Yu HY Jeong EM, Kim K, et al: Sirtl regulates DNA methylation and differentiation potential of embryonic stem cells by antagonizing Dnmt3l. Cell Rep 18: 1930-1945, 2017.

97. Guo Y, Wang M, Jia X, Zhu H, Zhi Y and Yuan L: Wnt signaling pathway upregulates DNMT1 to trigger NHERF1 promoter hypermethylation in colon cancer. Oncol Rep 40: 1165-1173, 2018

98.Zochbauer-Muller S, Gazdar AF and Minna JD: Molecular pathogenesis of lung cancer. Ann Rev Physiol 64: 681-708, 2002.

99. Nakajima NI, Niimi A, Isono M, Oike T, Sato H, Nakano T and Shibata A: Inhibition of the HDAC/Suv39/G9a pathway restores the expression of DNA damage-dependent major histocompatibility complex class I-related chain A and B in cancer cells. Oncol Rep 38: 693-702, 2017

100. Ferreira HJ, Heyn H, Garcia del Muro X, Vidal A, Larriba S, Muñoz C, Villanueva A and Esteller M: Epigenetic loss of the $\mathrm{PIWI}$ /piRNA machinery in human testicular tumorigenesis. Epigenetics 9: 113-118, 2014.

101. Sciamanna I, Vitullo P, Curatolo A and Spadafora C: A reverse transcriptase-dependent mechanism is essential for murine preimplantation development. Genes 2: 360-373, 2011.

102. Akers SN, Moysich K, Zhang W, Collamat Lai G, Miller A, Lele S, Odunsi K and Karpf AR: LINE1 and Alu repetitive element DNA methylation in tumors and white blood cells from epithelial ovarian cancer patients. Gynecol Oncol 132: 462-467, 2014.

103. Slotkin RK and Martienssen R: Transposable elements and the epigenetic regulation of the genome. Nat Rev Genet 8: 272-285, 2007.

104. Shilatifard A: Chromatin modifications by methylation and ubiquitination: Implications in the regulation of gene expression. Annu Rev Biochem 75: 243-269, 2006.

105. Grewal SI and Jia S: Heterochromatin revisited. Nat Rev Genet 8: 35-46, 2007.

106. Heard E: Delving into the diversity of facultative heterochromatin: The epigenetics of the inactive $\mathrm{X}$ chromosome. Curr Opin Genet Dev 15: 482-489, 2005

107. Corcoran AE: Immunoglobulin locus silencing and allelic exclusion. Semin Immunol 17: 141-154, 2005.

108. Skok JA, Gisler R, Novatchkova M, Farmer D, de Laat W and Busslinger M: Reversible contraction by looping of the Tcra and Tcrb loci in rearranging thymocytes. Nat Immunol 8: 378-387, 2007.

109. Klose RJ and Zhang Y: Regulation of histone methylation by demethylimination and demethylation. Nat Rev Mol Cell Biol 8 : 307-318, 2007.

110. Feldman N, Gerson A, Fang J, Li E, Zhang Y, Shinkai Y, Cedar $\mathrm{H}$ and Bergman Y: G9a-mediated irreversible epigenetic inactivation of $O c t-3 / 4$ during early embryogenesis. Nat Cell Biol 8: 188-194, 2006.

111. Lee E, Wang J, Jung Y, Cackowski FC and Taichman RS: Reduction of two histone marks, $\mathrm{H} 3 \mathrm{k} 9 \mathrm{me} 3$ and $\mathrm{H} 3 \mathrm{k} 27 \mathrm{me} 3$ by epidrug induces neuroendocrine differentiation in prostate cancer. J Cell Biochem 119: 3697-3705, 2018.

112. Ooi L and Wood IC: Chromatin crosstalk in development and disease: Lessons from REST. Nat Rev Genet 8: 544-554, 2007.

113. Shi Y: Histone lysine demethylases: Emerging roles in development, physiology and disease. Nat Rev Genet 8: 829-833, 2007.

114. Yang M, Gocke CB, Luo X, Borek D, Tomchick DR, Machius M, Otwinowski Z and Yu H: Structural basis for CoREST-dependent demethylation of nucleosomes by the human LSD1 histone demethylase. Mol Cell 23: 377-387, 2006.
115. Grewal SI and Elgin SC: Transcription and RNA interference in the formation of heterochromatin. Nature 447: 399-406, 2007.

116. Lee J, Ko J and Yi JY: Histone deacetylase inhibitor (HDACi) upregulates activin A and activates the Smad signaling pathway in melanomas. J Dermatol Sci 90: 13-20, 2017.

117. Terranova-Barberio M, Thomas S and Munster PN: Host histone acetylation unlocks HDAC inhibitor potential. Oncotarget 8: 106161-106162,2017.

118. Liu C, Liu L, Chen X, Cheng J, Zhang H, Zhang C, Shan J, Shen J and Qian C: LSD1 stimulates cancer-associated fibroblasts to drive Notch3-dependent self-renewal of liver cancer stem-like cells. Cancer Res 78: 938-949, 2018

119. Fei W, Chen L, Chen J, Shi Q, Zhang L, Liu S, Li L, Zheng L and Hu X: RBP4 and THBS2 are serum biomarkers for diagnosis of colorectal cancer. Oncotarget 8: 92254-92264, 2017.

120. Shi Y, Lan F, Matson C, Mulligan P, Whetstine JR, Cole PA, Casero RA and Shi Y: Histone demethylation mediated by the nuclear amine oxidase homolog LSD1. Cell 119: 941-953, 2004

121. Smith CD, Shu S, Mungall CJ and Karpen GH: The Release 5.1 annotation of Drosophila melanogaster heterochromatin. Science 316: 1586-1591, 2007.

122. Smallwood A, Esteve PO, Pradhan S and Carey M: Functional cooperation between HP1 and DNMT1 mediates gene silencing. Genes Dev 21: 1169-1178, 2007

123. Peters AH, O'Carroll D, Scherthan H, Mechtler K, Sauer S, Schöfer C, Weipoltshammer K, Pagani M, Lachner M, Kohlmaier A, et al: Loss of the Suv39h histone methyltransferases impairs mammalian heterochromatin and genome stability. Cell 107: 323-337, 2001.

124. Yoon KA, Hwangbo B, Kim IJ, Park S, Kim HS, Kee HJ, Lee JE, Jang YK, Park JG and Lee JS: Novel polymorphisms in the SUV39H2 histone methyltransferase and the risk of lung cancer. Carcinogenesis 27: 2217-2222, 2006

125. Zhao Z, Hu Y, Shen X, Lao Y, Zhang L, Qiu X, Hu J, Gong P, Cui $\mathrm{H}, \mathrm{Lu} \mathrm{S}$, et al: HBx represses RIZ1 expression by DNA methyltransferase 1 involvement in decreased miR-152 in hepatocellular carcinoma. Oncol Rep 37: 2811-2818, 2017.

126. Gibbons RJ: Histone modifying and chromatin remodelling enzymes in cancer and dysplastic syndromes. Hum Mol Genet 14: R85-R92, 2005.

127. Lakshmikuttyamma A, Takahashi N, Pastural E, Torlakovic E, Amin HM, Garcia-Manero G, Voralia M, Czader M, DeCoteau JF and Geyer CR: RIZ1 is potential CML tumor suppressor that is down-regulated during disease progression. J Hematol Oncol 2: 28, 2009.

128. Espino PS, Drobic B, Dunn KL and Davie JR: Histone modifications as a platform for cancer therapy. J Cell Biochem 94 1088-1102, 2005.

129. Hamamoto R, Furukawa Y, Morita M, Iimura Y, Silva FP, Li M, Yagyu R and Nakamura Y: SMYD3 encodes a histone methyltransferase involved in the proliferation of cancer cells. Nat Cell Biol 6: 731-740, 2004

130.Li W, Zhang X, Lu X, You L, Song Y, Luo Z, Zhang J, Nie J, Zheng W, Xu D, et al: 5-Hydroxymethylcytosine signatures in circulating cell-free DNA as diagnostic biomarkers for human cancers. Cell Res 27: 1243-1257, 2017.

131. Pulukuri SM, Estes N, Patel J and Rao JS: Demethylation-linked activation of urokinase plasminogen activator is involved in progression of prostate cancer. Cancer Res 67: 930-939, 2007.

132. Stepanova V, Dergilev KV, Holman KR, Parfyonova YV, Tsokolaeva ZI, Teter M, Atochina-Vasserman EN, Volgina A, Zaitsev SV, Lewis SP, et al: Urokinase-type plasminogen activator (uPA) is critical for progression of tuberous sclerosis complex 2 (TSC2)-deficient tumors. J Biol Chem 292: 20528-20543, 2017

133. Foekens JA, Peters HA, Look MP, Portengen H, Schmitt M, Kramer MD, Brünner N, Jänicke F, Meijer-van Gelder ME, Henzen-Logmans SC, et al: The urokinase system of plasminogen activation and prognosis in 2780 breast cancer patients Cancer Res 60: 636-643, 2000.

134. Miyake H, Hara I, Yamanaka K, Gohji K, Arakawa S and Kamidono S: Elevation of serum levels of urokinase-type plasminogen activator and its receptor is associated with disease progression and prognosis in patients with prostate cancer. Prostate 39: 123-129, 1999.

135. Zhang Z, Wang J, Wang X, Song W, Shi Y and Zhang L: MicroRNA-21 promotes proliferation, migration, and invasion of cervical cancer through targeting TIMP3. Arch Gynecol Obstet 297: 433-442, 2018 . 
136. Qi JH, Ebrahem Q, Moore N, Murphy G, Claesson-Welsh L, Bond M, Baker A and Anand-Apte B: A novel function for tissue inhibitor of metalloproteinases-3 (TIMP3): Inhibition of angiogenesis by blockage of VEGF binding to VEGF receptor-2 . Nat Med 9: 407-415, 2003.

137. Cui H, Hu Y, Guo D, Zhang A, Gu Y, Zhang S, Zhao C, Gong P, Shen X, Li Y, et al: DNA methyltransferase $3 A$ isoform b contributes to repressing E-cadherin through cooperation of DNA methylation and $\mathrm{H} 3 \mathrm{~K} 27 / \mathrm{H} 3 \mathrm{~K} 9$ methylation in EMT-related metastasis of gastric cancer. Oncogene 37: 4358-4371, 2018.

138. Filbin MG, Tirosh I, Hovestadt V, Shaw ML, Escalante LE, Mathewson ND, Neftel C, Frank N, Pelton K, Hebert CM, et al: Developmental and oncogenic programs in H3K27M gliomas dissected by single-cell RNA-seq. Science 360: 331-335, 2018.

139. Gregory PA, Bracken CP, Bert AG and Goodall GJ: MicroRNAs as regulators of epithelial-mesenchymal transition. Cell Cycle 7: 3112-3118, 2008

140. Suarez Y and Sessa WC: MicroRNAs as novel regulators of angiogenesis. Circ Res 104: 442-454, 2009.

141. Liang Z, Wu H, Reddy S, Zhu A, Wang S, Blevins D, Yoon Y, Zhang Y and Shim H: Blockade of invasion and metastasis of breast cancer cells via targeting CXCR4 with an artificial microRNA. Biochem Biophys Res Commun 363: 542-546, 2007.
142. Henderson IR and Jacobsen SE: Epigenetic inheritance in plants. Nature 447: 418-424, 2007.

143. Wassenegger M, Heimes S, Riedel L and Sanger HL: RNA-directed de novo methylation of genomic sequences in plants. Cell 76: 567-576, 1994.

144. Seitz H, Youngson N, Lin SP, Dalbert S, Paulsen M, Bachellerie JP, Ferguson-Smith AC and Cavaillé J: Imprinted microRNA genes transcribed antisense to a reciprocally imprinted retrotransposon-like gene. Nat Genet 34: 261-262, 2003.

145. Lin SP, Coan P, da Rocha ST, Seitz H, Cavaille J, Teng PW, Takada S and Ferguson-Smith AC: Differential regulation of imprinting in the murine embryo and placenta by the Dlk1-Dio3 imprinting control region. Development 134: 417-426, 2007.

146. Sinkkonen L, Hugenschmidt T, Berninger P, Gaidatzis D, Mohn F, Artus-Revel CG, Zavolan M, Svoboda P and Filipowicz W: MicroRNAs control de novo DNA methylation through regulation of transcriptional repressors in mouse embryonic stem cells. Nat Struct Mol Biol 15: 259-267, 2008.

147. Benetti R, Gonzalo S, Jaco I'Muñoz P, Gonzalez S, Schoeftner S, Murchison E, Andl T, Chen T and Klatt P: A mammalian microRNA cluster controls DNA methylation and telomere recombination via Rbl2-dependent regulation of DNA methyltransferases. Nat Struct Mol Biol 15: 268-279, 2008. 